\title{
Partial Characterization of Antigenic Streptococcal \\ Plasma Membrane Components in Acute Glomerulonephritis
}

\author{
G. Treser, M. Semar, A. Ty, I. Sagel, M. A. Frankin, and K. Lange \\ From the Renal Service and Laboratory, Departments of Medicine and \\ Pediatrics, and Department of Microbiology, New York Medical College, \\ New York 10029
}

A в S T R A C T Fluorescein-labeled immunoglobulin G (IgG) fractions of serum from patients with acute poststreptococcal glomerulonephritis stained parts of the glomerular basement membrane and mesangium of kidney tissue obtained from the same patients during the early phase of the disease. Renal tissue obtained from normal individuals and from patients with other kidney diseases failed to stain with these IgG fractions. Preabsorption of the serum fractions with various freezethawed bacteria demonstrated that only certain group A streptococci abolished the staining capacity. Fractionation of the streptococci into cellular constituents indicated that it was predominantly the plasma membrane fraction which blocked the immune staining. Spectrofluorometry using alkali-solubilized renal tissue confirmed these observations in a quantitative manner. By sucrose density-gradient ultracentrifugation of the plasma membrane two possible antigens were isolated. One was soluble in phosphate-buffered saline and the other was insoluble. The soluble component was a lipoprotein with a molecular weight of approximately 120,000.

\section{INTRODUCTION}

An infection with group A streptococci generally precedes acute glomerulonephritis and is considered an etiologic factor. Seegal, Andres, Hsu, and Zabriskie (1) and Michael, Drummond, Good, and Vernier (2), using fluorescent antibodies to the streptococcus, have been able to show streptococcal components on the glomeruli in some instances. Markowitz and Lange (3) have suggested a cross-reaction between a component of the glomerular basement membrane and the streptococcal plasma membrane.

This work was presented in part at the annual meeting of the Association of American Physicians, 6 May 1969, Atlantic City, N. J.

Received for publication 10 July 1969 and in revised form 15 October 1969.
In previous studies we were able to show that streptococcal plasma membrane constituents can be demonstrated on the glomerular basement membrane during the early phase of acute glomerulonephritis (4). The present report is concerned with the isolation and partial characterization of specific antigenic fractions of the streptococcal plasma membrane. Both immunohistology and quantitative comparative fluorometry were employed.

\section{METHODS}

Percutaneous kidney biopsies using the Franklin modification of the Vim-Silverman needle were performed on 16 children and three adults within 5 days after onset of acute poststreptococcal glomerulonephritis. Repeat biopsy specimens were obtained on two of these patients after 3 months. The diagnosis of acute glomerulonephritis was established by the presence of proteinuria, hematuria, red blood cell casts in the urine, lowered serum complement activity $\left(\mathrm{CH}_{30}\right)$ (5), and an increasing anti-streptolysin-O titer. 38 renal tissue specimens were used as control. The diseases studied and number of specimens of each were: subacute glomerulonephritis, 5; chronic glomerulonephritis, 7 ; diabetic nephropathy, 3; systemic lupus erythematosus, 2; discoid lupus, 1 ; pyelonephritis, 5 ; pure nephrosis, 2, acute glomerulonephritis, 8; and normal kidney tissue, 5 . In the control patients with acute glomerulonephritis, biopsies were obtained 3-8 wk after onset of the disease.

Specimens for light microscopy were fixed in $10 \%$ formalin, buffered with Zenkers solution or $2 \%$ sodium acetate to a $\mathrm{pH} 7$, and embedded in paraffin. Sections $2-3 \mu$ thick were stained with hematoxylin and eosin, periodic acid Schiff, and periodic acid silver methenamine.

Specimens for immunohistology were prepared by immediately embedding the biopsy cylinder in fresh rat liver and freezing it for $3 \mathrm{~min}$ in an isopentane dry ice mixture (6). Sections of $3 \mu$ thickness were cut at $-20^{\circ} \mathrm{C}$ in a cryostat, air dried, stained with fluorescein isothiocyanate (FIT)labeled immune sera for $30 \mathrm{~min}$ in a moist chamber, and washed with $0.01 \mathrm{M}$ phosphate-buffered normal saline (PBS) at $\mathrm{pH} 7.1$. A drop of buffered glycerol, $\mathrm{pH} 7.1$, and a cover glass were placed on each section. They were examined under a Leit ${ }^{1}$ UV microscope with a $200 \mathrm{w}$ Osram B high-tension mercury vapor bulb and photographed with $a$

${ }^{1}$ E. Leitz, Inc., New York. 
Leitz Orthomat camera using Anscochrome 200 outdoor film.

Glomeruli were prepared by the method of Krakower and Greenspon (7) as modified by Spiro (8). Three metal sieves were used with the glomeruli finally being collected on the 150 wires per inch mesh. The glomeruli were then freeze-thawed five times and centrifuged at 10,000 $g$. Lyophilized samples of disrupted glomeruli were used for preabsorption studies.

Gamma globulin (IgG) was obtained by precipitation of sera with diaminoethoxyacrydine (Rivanol) (9), and by DEAE chromatography according to the method of Sober, Gutter, Wyckoff, and Peterson (10). Immunoelectrophoresis using Veronal buffer, $\mathrm{pH} 8.6$, showed one band for $\mathrm{IgG}$ globulin. The fractions were labeled with fluorescein isothiocyanate (11), and the unreacted fluorescein was removed by gel filtration through Sephadex G-25. All labeled fractions were adsorbed with fresh homogenized rat liver in a $1: 1$ ratio. High titered rabbit antisera against human IgG and $\beta_{1 \mathrm{c}}-\beta_{1 \mathrm{a}}{ }^{2}$ were prepared in our laboratory.

The procedure for determining the fluorescein concentration (12) was as follows: sequential sections of a given kidney biopsy specimen were cut at a $3 \mu$ setting and placed in individual $50-\mathrm{ml}$ beakers. Only sections of uniform size were used. After prewashing they were stained with the respective fluorescein-labeled sera, and then washed with PBS until the fluorometer ${ }^{3}$ showed a zero reading for the final wash. The sections were then digested at $60^{\circ} \mathrm{C}$ for 12 hr with $10 \mathrm{ml}$ of $20 \% \mathrm{NaOH}$ and the fluorescence of the digest read in the fluorometer. Since the degree of proteinfluorescein conjugation varies slightly from batch to batch, studies were always performed with specimens from the same batch of labeled $\operatorname{IgG}$ stored in small vials at $-20^{\circ} \mathrm{C}$. A linear relationship was maintained between concentration of fluorescein and fluorometric reading under these conditions. Moreover, quenching and light scattering did not alter the results. The fluorometer was standardized before each use by means of a $50 \mathrm{~m} \mu \mathrm{g} / 100 \mathrm{ml}$ sodium fluorescein solution at $\mathrm{pH}$ 7.2. This reference standard was kept in a dark brown bottle at $4^{\circ} \mathrm{C}$ and used at room temperature. In order to determine nonspecific staining and tissue autofluorescence $0.5 \mathrm{ml}$ of the patients' labeled IgG fractions was preabsorbed with $10 \mathrm{mg}$ of lyophilized rabbit anti-human IgG for $3 \mathrm{hr}$ at $37^{\circ} \mathrm{C}$. The readings obtained after staining with these inactive IgG fractions were subtracted from all the fluorometry results.

Three strains of group A streptococci were isolated from the pharynx of patients with acute glomerulonephritis; two were Type 12 and one was nontypeable. Streptococcus group A Type 6 was isolated from the pharynx of a healthy subject. One strain each of Streptococcus mitis, Streptococcus fecalis, Escherichia coli, and Staphylococcus epidermidis was obtained from normal subjects. A strain of Staphylococcus aureus was isolated from the blood of a patient with fatal septicemia.

Each of the strains was grown for $20 \mathrm{hr}$ at $37^{\circ} \mathrm{C}$ in 250 $\mathrm{ml}$ of brain-heart infusion broth. ${ }^{4}$ The medium was removed and the cells were washed twice in physiological saline and five times in Sorensen's phosphate buffer at $\mathrm{pH}$ 7.4. All

\footnotetext{
${ }^{2}$ Kindly supplied by Dr. Müller-Eberhard, Scripps Institute, La Jolla, Calif.

${ }^{3}$ Turner Fluorometer, model 110, G. K. Turner Associates, Inc., Palo Alto, Calif.

- Difco Labs, Detroit, Mich.
}

washes were performed in a Sorvall ${ }^{5}$ RC-2 centrifuge at $17,000 \mathrm{~g}$ for $40 \mathrm{~min}$ at $4^{\circ} \mathrm{C}$.

Cell walls were prepared in a Ribi cell fractionator (Sorvall) at $36,000 \mathrm{psi}$ or alternatively according to the method of Bleiweiss, Karakawa, and Krause (13).

Streptococcal $M$ protein was obtained according to the method of Fox (14).

Streptococcal plasma membranes were prepared by group C phage-associated lysin as described by Freimer (15) with the modifications of Zabriskie and Freimer (16).

Rhamnose was determined by the method of Dische and Shettles (17) and glucosamine by the Rondle and Morgan procedure (18).

The various intact bacteria were disrupted by freezethawing five times in a dry-ice-acetone mixture; the supernatant was discarded. The sediment was washed with distilled water and lyophilized.

Preabsorption studies were performed in all instances by incubating varying amounts of lyophilized bacterial sediments, streptococcal fractions, or human glomeruli with $1 \mathrm{ml}$ of the patients' FIT-labeled IgG fractions. Incubation temperature was at $37^{\circ} \mathrm{C}$ and maximum absorption was found to occur at $3 \mathrm{hr}$. As a control the labeled IgG was diluted with buffer in equal amounts or adsorbed with inert cellulose.

The technique of Martin and Ames (19) was used to produce linear $5-40 \%$ sucrose gradients in a $10 \mathrm{ml}$ volume. Samples $(0.2 \mathrm{ml})$, layered on the gradients, were centrifuged at $38,000 \mathrm{rpm}$ for $20 \mathrm{hr}$ at a chamber temperature of $4^{\circ} \mathrm{C}$ in a type 50 rotor. $^{6}$ Each Lusteroid centrifuge tube was emptied by piercing the bottom with a fine gauge needle, collecting 15-20 fractions of $0.5 \mathrm{ml}$ each. To monitor the efficiency of protein separation and permit molecular weight comparisons, each run included $0.2 \mathrm{ml}$ of a mixture of $0.1 \%$ human gamma globulin, ${ }^{7}$ and $0.1 \%$ Dextran Blue. ${ }^{8}$ The optical density was read in a Beckman DB spectrophotometer ${ }^{\circ}$ at $280 \mathrm{~m} \mu$.

Cellulose acetate electrophoresis was performed using the Millipore $^{10}$ apparatus with barbital buffer $\mathrm{pH} 8.6$ and Ponceau S stain. Protein was estimated by the biuret procedure using bovine albumin as the standard (20) and hexose analysis was carried out by the anthrone method (21) with glucose as standard. The amount of nitrogen in the samples was determined with a $\mathrm{CHN}$ analyzer. ${ }^{11}$ The standards for nitrogen were $(a)$ cystine $^{12} \mathrm{~N}=11.66 \%$ and (b) crystalized bovine plasma albumin ${ }^{13} \mathrm{~N}=15.8 \%$. Lipid analysis was performed by the Folch extraction procedure (22).

\footnotetext{
${ }^{5}$ Ivan Sorvall, Norwalk, Conn.

' Model L-2 Spinco Ultracentrifuge, Beckman Instruments, Inc., Palo Alto, Calif.

${ }^{7}$ Molecular weight markers, Mann Laboratories, New York.

${ }^{8}$ Pharmacia Fine Chemicals, Piscataway, N. J.

- Model DB Spectrophotometer, Beckman Instruments, Inc., Palo Alto, Calif.

${ }^{10}$ Millipore Corp., Bedford, Mass.

${ }^{11} \mathrm{CHN}$ Analyzer, model $185 \mathrm{~F} \& \mathrm{M}$ Scientific, Philadelphia, Penn.

${ }^{12}$ U. S. Dept. of Commerce, National Bureau of Standards, Office of Standard Reference Materials, Washington, D. C.

${ }^{13}$ Armour Pharmaceutical Co., Kankakee, Ill.
} 

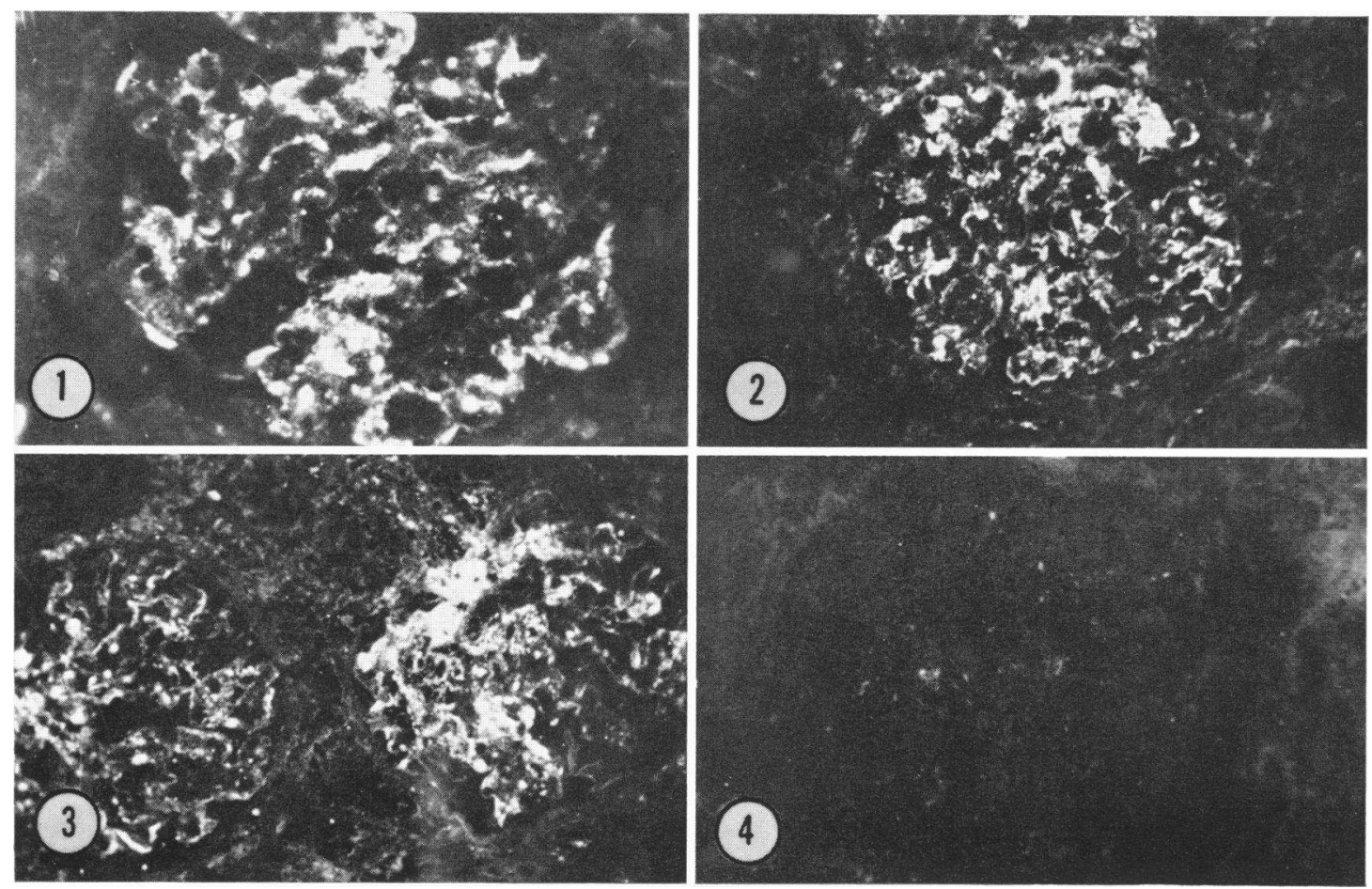

Figure 1 One glomerulus from the renal biopsy of a patient with acute poststreptococcal glomerulonephritis, stained with the patient's own FIT-labeled IgG fraction. The biopsy specimen was obtained 2 days after onset of symptoms. Fluorescent deposits primarily on the basement membrane and in the mesangium are granular. $\times 450$.

FIgURE 2 One glomerulus from the same patient as in Fig. 1, stained with the FIT-labeled IgG fraction of a different patient with acute poststreptococcal glomerulonephritis. $\times 250$.

Figure 3 Two glomeruli from the same patient as in Fig. $1.1 \mathrm{ml}$ of the patient's own FITlabeled $\operatorname{IgG}$ fraction was incubated with $5 \mathrm{mg}$ freeze-thawed normal human glomeruli for $3 \mathrm{hr}$ at $37^{\circ} \mathrm{C}$ before staining the biopsy. There was no change in fluorescent staining pattern and intensity compared to Fig. 1. $\times 250$.

Figure 4 One glomerulus from the same patient as in Fig. $1.1 \mathrm{ml}$ of the patient's own labeled IgG was incubated for $3 \mathrm{hr}$ at $37^{\circ} \mathrm{C}$ with $5 \mathrm{mg}$ of the soluble fraction (peak 2) obtained by sucrose gradient-density ultracentrifugation. There was almost complete elimination of the fluorescent staining with this antigenic fraction. $\times 250$.

\section{RESULTS}

Light microscopy of the kidney biopsy sections of the patients with acute poststreptococcal glomerulonephritis showed characteristic hypercellularity, polymorphonuclear infiltration, impingement on capillary lumina, and some diffuse mesangial proliferation. Fluoresceinlabeled antisera against human IgG and human $\beta_{1 \mathrm{c}}-\beta_{1 \mathrm{a}}$ stained the glomerular basement membranes and parts of the mesangium in a granular pattern.

The FIT-labeled IgG fractions of the sera of 19 patients with acute poststreptococcal glomerulonephritis (FIgG AGN) stained the glomerular basement membrane and parts of the mesangium of their own biopsy sections in a segmental pattern (Fig. 1). A similar staining pattern was observed when the FIgG AGN were used interchangeably on any of the 19 biopsy specimens obtained in the early phase of acute glomerulonephritis (Fig. 2). FIgG AGN obtained within the 1st week of the disease showed less staining than the fractions obtained $2-8$ wk later when applied to the preserved section of the same early biopsies, giving a difference of fluorometric reading of at least $30 \%$.

Blocking tests using unlabeled IgG fractions of the patients' sera before the actual staining were performed in all instances and resulted in a marked reduction or complete elimination of fluorescent staining both by immunohistologic evaluation and quantitative fluorometry readings.

Two patients, whose renal tissue obtained during the first 5 days of acute glomerulonephritis showed intense staining with FIgG AGN, had a repeat biopsy 90 days later. These later biopsy specimens continued to show 
staining of the glomerular basement membrane and parts of the mesangium with labeled anti-human IgG and complement. They failed, however, to stain with FIgG AGN. Similarly, biopsy sections of patients with acute glomerulonephritis obtained later, e.g. 3-8 wk after clinical onset of the disease, did not stain with FIgG AGN. Renal tissue from patients with subacute glomerulonephritis, chronic glomerulonephritis, systemic lupus erythematosus, pure nephrosis, diabetic nephropathy, discoid lupus, and pyelonephritis failed to stain with FIgG AGN. Normal renal tissue also did not stain.

Incubation of $1 \mathrm{ml} \mathrm{FIgG} \mathrm{AGN} \mathrm{with} 5 \mathrm{mg}$ of freezethawed normal human glomeruli did not reduce the staining capacity of FIgG AGN when tested on kidney sections of patients with early acute poststreptococcal glomerulonephritis (Fig. 3).

The staining capacity of FIgG AGN was reduced after incubation with the sediment of freeze-thawed streptococci $(5 \mathrm{mg})$ isolated from patients with acute poststreptococcal glomerulonephritis. The reductions in fluorometer readings were $76 \%$ for group A nontypeable strain and 74 and $71 \%$ for the two group A type 12 strains.

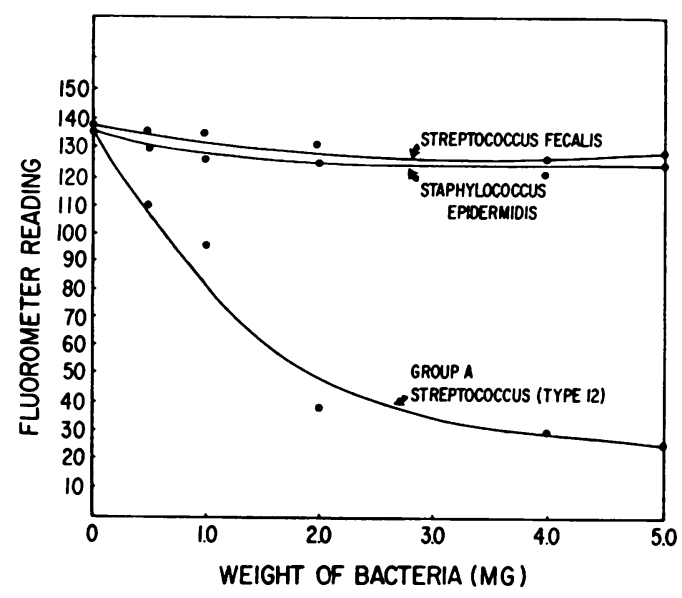

FIGURE 5 Effects of various bacteria on the staining capacity of fluorescein labeled IgG fractions of patients with acute poststreptococcal glomerulonephritis. The 19 FITlabeled IgG fractions $(1 \mathrm{ml})$ were incubated at $37^{\circ} \mathrm{C}$ for $3 \mathrm{hr}$ with the varying amounts of bacterial sediments, centrifuged at $10,000 \mathrm{RPM}$ for $10 \mathrm{~min}$ and applied to the biopsy specimens. Fluorescence was read after the removal of unreacted FIT-labeled IgG and digestion of the tissue with $20 \% \mathrm{NaOH}$. The values were all subtracted from the readings obtained with a patient's labeled IgG which was preabsorbed with anti-human gamma globulin $(10 \mathrm{mg})$. This inactive gamma globulin gave baseline values of nonspecific fluorescence and the native fluorescence of the tissue alone. The figure represents a typical result, when one patient's IgG was used after preabsorption with the bacteria on his own renal tissue. This particular biopsy contained an unusually large number of glomeruli (76 per section), thus giving a high control reading.

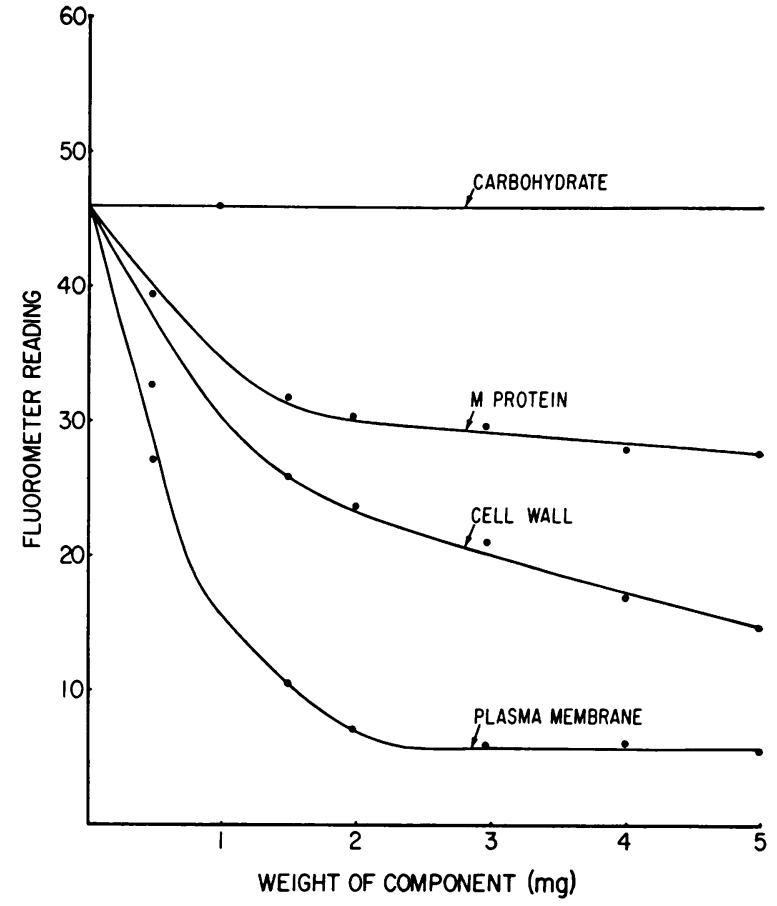

Figuke 6 Effects of various streptococcal components (group A, Type 12) on the staining capacity of the 19 fluorescein labeled IgG fractions of patients with acute poststreptococcal glomerulonephritis. This strain was obtained from the throat of a patient with acute glomerulonephritis. Varying amounts of the above components were incubated with the labeled IgG fractions and the resulting readings corrected as described in Fig. 5. This figure represents the average results using the 19 labeled IgGs with the 19 different biopsy specimens.

Preabsorption with freeze-thawed $(5 \mathrm{mg})$ Streptococcus fecalis, Staphylococcus epidermis, streptococcus group A Type 6, Streptococcus mitis, Escherichia coli, and Staphylococcus aureus failed to reduce materially the degree of staining with FIgG AGN. Fig. 5 shows the quantitative effect of preabsorption with some of the above mentioned bacteria.

By incubating FIgG AGN with purified components of the group A Type 12 streptococci, e.g. cell wall, M protein, and plasma membrane, as well as group Aspecific carbohydrate, ${ }^{14}$ the absorptive properties of these constituents were tested. The highest degree of blocking was observed with plasma membrane (Fig. 6).

Streptococcal plasma membrane solubilized with $8 \mathrm{~m}$ urea, $0.6 \%$ desoxycolate, $4 \mathrm{~m}$ guanidine, detergents ( $1 \%$ Tween 80 or $1 \%$ sodium lauryl sulfate), trypsin, papain, $0.05 \mathrm{~N} \mathrm{HCI}$, and $0.05 \mathrm{~N} \mathrm{NaOH}$ lost its blocking ability to a great extent or completely. Streptococcal plasma membrane was therefore partially solubilized in phos-

\footnotetext{
${ }^{14}$ Kindly supplied by Dr. John B. Zabriskie, The Rocke-
} feller University, New York. 
phate-buffered saline by vigorous mixing in a tissue grinder. This PBS-solubilized membrane was used for sucrose density-gradient studies. Three peaks and a precipitate were reproducibly obtained in seven individual runs in the ultracentrifuge with a sucrose gradient $(5-40 \%)$. Preabsorption studies of FIgG AGN with these fractions revealed that one soluble fraction and the precipitate markedly reduced the staining capacity of the FIgG AGN (Figs. 4 and 7). There was an average reduction in fluorometer readings of $79 \%$ when FIgG AGN was incubated with $5 \mathrm{mg}$ of the lyophilized fraction of peak 2 and a $63 \%$ reduction with the precipitate. Fractions obtained from peak 1 and peak 3 did not alter the staining capacity of FIgG AGN.

The soluble component had a molecular weight of approximately 120,000 . This antigenic fraction was heterogenous (three bands) by cellulose acetate electrophoresis with a mobility in the gamma globulin region. Chemical analysis showed that it contained $13.6 \% \mathrm{ni}$ trogen and $85 \%$ protein (biuret), $1.5 \%$ hexose, and a total lipid content of $10.95 \%$.

\section{DISCUSSION}

In order to demonstrate the specific antigens in acute poststreptococcal glomerulonephritis it was necessary to study tissue obtained in the early phase of the disease. The kidney biopsies were taken from the 19 patients in our series not more than 5 days after onset of symptoms. In two of these patients who had repeat biopsies after 90 days, and in eight patients biopsied for the first time 3-8 wk after onset, the glomeruli did not stain with FIgG AGN while staining was positive with anti-human IgG and complement. Feldman and Drummond (23) also observed fluorescent staining predominantly in the early phase of acute glomerulonephritis. These authors, however, used antisera produced in animals against group A streptococcal products.

Staining with FIgG AGN in the early phase may be attributed to the possibility that not all antigenic sites on the glomerulus are as yet fully saturated. A lack of staining 2 months later may be explained by full saturation of these antigenic sites, alteration of the antigen or its removal, although the persistence of staining for IgG and complement makes the latter two interpretations unlikely.

Whereas renal tissue must be obtained during the early phase of the disease for positive staining results with FIgG AGN, serum obtained 2-8 wk after onset had an even greater staining capacity than the early samples. This finding agrees with the observation of

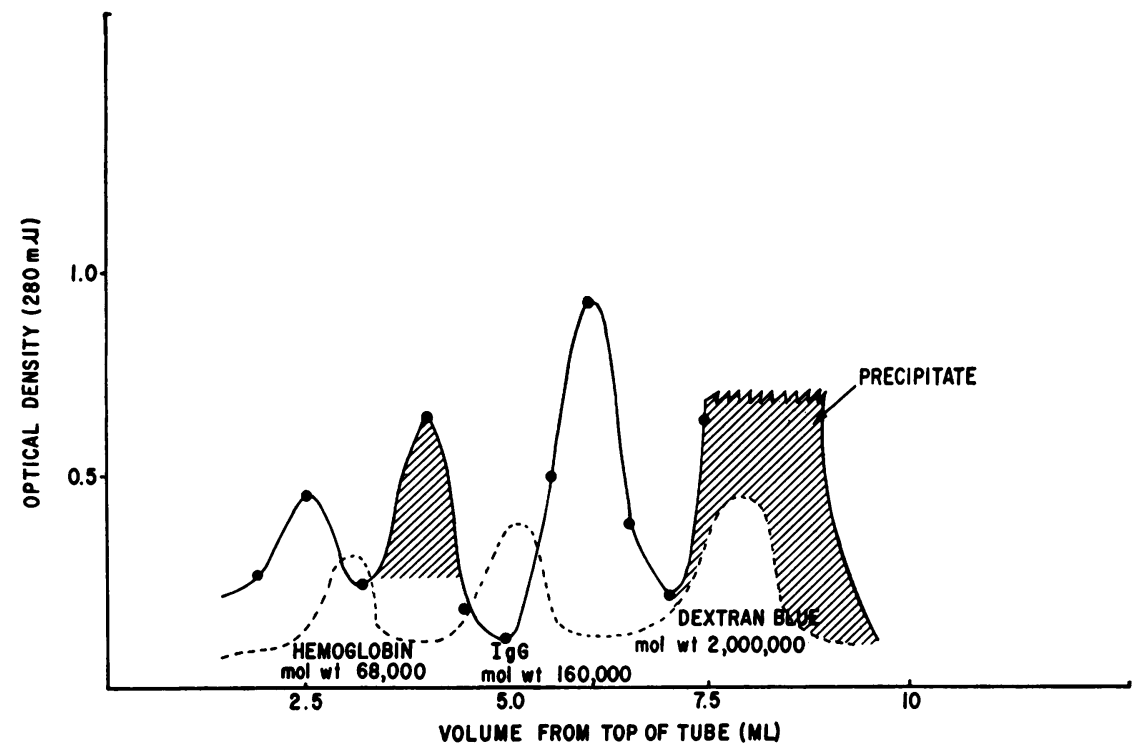

Figure 7 Sucrose density-gradient ultracentrifugation of a phosphate buffered saline $\mathrm{pH} 7.1$ solubilized streptococcal plasma membrane (group A, Type 12). The ordinate records the concentration of protein as a function of absorbance at $280 \mathrm{~m} \mu$. Linear gradients $5-40 \%$ sucrose at $38,000 \mathrm{rpm}$ for $20 \mathrm{hr}$ with type 50 rotor, model L-2 Spinco. $0.2 \mathrm{ml}$ of homogenized sample was used and $0.5 \mathrm{ml}$ fractions were collected by puncturing the bottom of the centrifuge tubes. The four fractions (three soluble peaks and a precipitate) were dialyzed and lyophilized. Incubation studies as described in Fig. 5 indicated that the peaks of the two shaded areas blocked the positive staining capacity of the labeled IgG. In some instances, the precipitate was solubilized in $0.05 \mathrm{~N} \mathrm{NaOH}$ in order to obtain a spectrophotometer reading. The optical density was $\mathbf{0 . 9 9 5}$. 
increasing streptococcal antibody titers in patients with acute glomerulonephritis following the initial phase of the disease $(24,25)$.

The possibility that hidden antigenic sites are present in normal glomeruli and are uncovered in acute glomerulonephritis was considered. The fact, however, that FIgG AGN when incubated with freeze-thawed normal human glomeruli did not change its staining capacity, that is, did not react with glomerular substance, makes this speculation doubtful.

Kidney biopsy sections from patients with various other renal diseases as well as normal kidney tissue failed to stain with any of the FIgG AGN. This finding strongly indicates a specific immunologic reaction occurring in the early phase of acute poststreptococcal glomerulonephritis.

Various bacteria were tested for their absorptive properties, but only group A streptococci isolated from patients with acute glomerulonephritis eliminated the positive staining capacity of FIgG AGN. These sera, when not preabsorbed with nephritogenic streptococci stained certain loci in the glomeruli in early acute glomerulonephritis. This appears to be indirect evidence of the presence of group A streptococcal components in the kidney.

It was difficult to obtain the streptococcal components in a highly purified form. Cell wall preparations are contaminated with up to $30 \%$ plasma membrane, as shown by Zabriskie and Freimer (16). Our M protein preparations were relatively purified, but, as suggested by Beachey, Alberti, and Stollerman (26), many of the highly purified $M$ protein preparations available may still be contaminated with plasma membrane components. Since the streptococcal plasma membrane used in our studies contained less than $0.1 \%$ rhamnose and no glucosamine, we considered the preparation reasonably purified. The cell wall and $M$ protein blocked the positive staining of the FIgG AGN to some extent, but plasma membrane had by far the greatest absorptive effect (Fig. 6). The slight reduction in fluorescence with $M$ protein and cell wall preparations may have been due to membrane contamination. The possibility, however, that components in our $\mathrm{M}$ protein and cell wall fractions not related to plasma membrane may also be antigenic cannot be excluded.

Many substances which completely solubilize the plasma membrane destroyed its antigenic properties. Saline phosphate buffer was therefore used for partial solubilization of the membrane in the sucrose gradient studies since it left the antigenic properties unaffected. There may have been losses of the soluble antigenic component during preparation of the streptococcal plasma membrane since a phosphate-buffered saline was used in the washing procedures. The samples used for the ultracentrifugation studies, however, were vigorously mixed in a tissue grinder for one hour in order to increase solubility. Mixing for $24 \mathrm{hr}$ did not increase the amount of soluble fractions.

The decrease in fluorescence observed with the nephritogenic streptococci and the streptococcal components was reproducible and each point in the figures shown represents the average of at least 15 individual determinations. The ordinates in the figures are given in actual fluorometer readings because we feel it is the most direct way to represent the data. Many attempts were made to relate the fluorometer readings to equivalent amounts of patients' labeled IgG or even an inert gamma globulin. This proved to be misleading since the exact amount of streptococcal antibodies present in the total gamma globulin is not yet known. The difference in fluorometric readings obtained after incubation of FIgG AGN with freeze-thawed streptococci (Fig. 5) and streptococcal plasma membrane (Fig. 6) may be due to the fact that freeze-thawing does not completely liberate the plasma membrane fraction.

The soluble fraction capable of blocking the FIgG AGN was characterized as a lipoprotein with a molecular weight of approximately 120,000 . The detection of streptococcal plasma membrane components apparently present on the glomerular basement membrane in the early phase of acute poststreptococcal glomerulonephiritis strongly suggests an immunopathogenic mechanism involving antigen of nonglomerular origin.

\section{ACKNOWLEDGMENTS}

We gratefully acknowledge the help and advice of Dr. John Zabriskie of The Rockefeller University, Dr. Mervyn Franklin of the Department of Microbiology of New York Medical College during the course of these studies, and Dr. Martin Horowitz of the Department of Biochemistry, New York Medical College, for his assistance in the ultracentrifugation studies. We are indebted to Mr. Pedro Burgos and Mrs. Drucella Bond for their technical assistance.

This work was supported by Grant No. AM 10672 from the National Institutes of Arthritis and Metabolic Diseases, National Institutes of Health.

\section{REFERENCES}

1. Seegal, B. C., G. A. Andres, K. C. Hsu, and J. B. Zabriskie. 1965. Studies on the pathogenesis of acute and progressive glomerulonephritis in man by immunofluorescein and immunoferritin techniques. Fed. Proc. 24: 100.

2. Michael, A. F., Jr., K. N. Drummond, R. A. Good, and R. L. Vernier. 1966. Acute poststreptococcal glomerulonephritis. Immune deposit disease. J. Clin. Invest. 45: 237.

3. Markowitz, A. S., and C. F. Lange, Jr. 1964. Streptococcal related glomerulonephritis. I. Isolation, immunochemistry and comparative chemistry of soluble fractions from Type 12 nephritogenic streptococci and human glomeruli. J. Immunol. 92 : 565. 
4. Treser, G., M. Semar, M. McVicar, M. Franklin, A. Ty, I. Sagel, and K. Lange. 1969. Antigenic streptococcal components in acute glomerulonephritis. Science (Washington). $163: 676$.

5. Lange, K., E. Wasserman, and L. B. Slobody. 1960. The significance of serum complement levels for the diagnosis and prognosis of acute and subacute glomerulonephritis and lupus erythematosus disseminatus. Ann. Intern. Med. 53: 636 .

6. Lange, K., G. Treser, I. Sagel, A. Ty, and E. Wasserman. 1966. Routine immunohistology in renal diseases. Ann. Intern. Med. 64: 25.

7. Krakower, C. A., and S. A. Greenspon. 1951. Localization of the nephrotoxic antigen within the isolated renal glomerulus. Arch. Pathol. 51: 629.

8. Spiro, R. G. 1967. Studies on the renal glomerular basement membrane. J. Biol. Chem. 242: 1915.

9. Saifer, A., and L. E. Lipkin. 1959. Electrophoretic and immunologic studies of Rivanol-fractionated serum proteins. Proc. Soc. Exp. Biol. Med. 102: 220.

10. Sober, H. A., F. J. Gutter, M. M. Wyckoff, and E. A. Peterson. 1956. Chromatography of proteins. II. Fractionation of serum protein on an ion exchange cellulose. J. Amer. Chem. Soc. 78: 756.

11. Riggs, J. L., P. C. Loh, and W. C. Eveland. 1960. A simple fractionation method for preparation of fluorescein-labeled gamma globulin. Proc. Soc. Exp. Biol. Med. $105: 655$.

12. Semar, M., G. Treser, and K. Lange. 1969. Quantitative comparative immunohistology. Clin. Chem. 15: 505.

13. Bleiweiss, A. S., W. W. Karakawa, and R. M. Krause. 1964. Improved technique for the preparation of streptococcal cell walls. J. Bacteriol. 88: 1198.

14. Fox. E. N. 1964. Antigenicity of the M proteins of group A hemolytic streptococci. J. Immunol. 93: 826.

15. Freimer, E. H. 1963. Studies of $\mathrm{L}$ forms and protoplasts of group A streptococci. II. Chemical and immunological properties of the cell membrane. J. Exp. Med. 117: 377.
16. Zabriskie, J. B., and E. H. Freimer. 1964. An immunological relationship between the group A streptococcus and mammalian muscle. J. Exp. Med. 124: 661 .

17. Dische, Z., and L. B. Shettles. 1948. A specific color reaction of methylpentoses and a spectrophotometric micromethod for their determination. J. Biol. Chem. 175: 595.

18. Rondle, C. J. M., and W. T. J. Morgan. 1955. The determination of glucosamine and galactosamine. Biochem. J. $61: 586$.

19. Martin, R. G., and B. N. Ames. 1961. A method for determining the sedimentation behavior of enzymes: application to protein mixtures. $J$ Biol. Chem. 236: 1372.

20. Layne, E. 1957. Spectrophotometric and turbidometric methods for measuring proteins. III. Biuret method. In Methods in Enzymology, Vol. 3. S. P. Colowick and N. O. Kaplan, editors. Academic Press Inc., New York. 3rd edition. 450.

21. Roe, J. H. 1955. The determination of sugar in blood and spinal fluid with anthrone reagent. J. Biol. Chem. 212 : 335 .

22. Folch, J., M. Lees, and G. H. Sloane Stanley. 1957. A simple method for the isolation and purification of total lipides from animal tissues. J. Biol. Chem. 226: 497.

23. Feldman, W., and K. N. Drummond. 1967. Immunopathologic studies in acute poststreptococcal glomerulonephritis. Transactions of the 37th Annual Meeting of the Society for Pediatric Research. 183.

24. Jennings, R. B., and D. P. Earle. 1961. Post-streptococcal glomerulonephritis: histopathologic and clinical studies of the acute, subsiding acute and early chronic latent phase. J. Clin. Invest. 40: 1525.

25. Rammelkamp, C. H., Jr. 1954. Acute hemorrhagic glomerulonephritis. In Streptococcal Infections. M. McCarty, editor. Columbia University Press, New York. 197.

26. Beachey, E. H., H. Alberti, and G. H. Stollerman. 1969. Delayed hypersensitivity to purified streptococcal $\mathbf{M}$ protein in guinea pigs and in man. J. Immunol. 102: 42. 